\title{
Continuous measurement of apparent Poisson's ratio for yarn based on omni-directional diameters
}

\author{
Masayuki Takatera ${ }^{1}$, Tamotsu Arichi ${ }^{2}$, Julie Peiffer ${ }^{3}$, Chunhong $\mathrm{Zhu}^{4}$, KyoungOk Kim ${ }^{1}$
}

${ }^{1}$ Division of Kansei and Fashion Engineering, Institute for Fiber Engineering (IFES), Interdisciplinary Cluster for Cutting Edge

Research (ICCER), Shinshu University,

3-15-1 Tokida, Ueda, Nagano 386-8567, Japan

Corresponding author e-mail: takatera@ shinshu-u.ac.jp

${ }^{2}$ Division of Textile \& Kansei Engineering, Graduate school of Science and Technology, Shinshu University, 3-15-1 Tokida, Ueda,

Nagano 386-8567, Japan

${ }^{3}$ Interdisciplinary Graduate School of Science and Technology, Shinshu University, 3-15-1 Tokida, Ueda, Nagano, 386-8567, Japan

${ }^{4}$ Faculty of Textile Science and Technology, Shinshu University, 3-15-1 Tokida, Ueda, Nagano 386-8567, Japan

\begin{abstract}
We proposed a new method of measuring apparent Poisson's ratio for yarn and developed a new tensile tester equipped with a digital micrometer that can measure the yarn's omni-directional diameter annularly while the yarn is elongated. Values of apparent Poisson's ratio were obtained from the longitudinal and transverse strains continuously. The mean diameter measured omnidirectionally was used to calculate the transverse strain for each longitudinal strain. We tested five spun yarns, one mono filament yarn and two filament yarns and obtained values of apparent Poisson's ratio against longitudinal strain for all samples. Apparent Poisson's ratio was not constant for spun and filament yarns while it was constant for monofilament yarn. When the longitudinal strain was low, apparent Poisson's ratios of ring spun yarns and filament yarns were large owing to the fiber packing density. As the longitudinal strain increased, apparent Poisson's ratio gradually decreased. Furthermore, we approximated the relationship between apparent Poisson's ratio and the longitudinal strain using a power function. The apparent Poisson values can be used in the simulation of fabrics.
\end{abstract}

\section{Introduction}

The mechanical properties of yarns need to be known for the mechanical analysis and simulation of fabrics. Among the mechanical properties, tension, transverse compression, bending, torsion, and Poisson's ratio in tensile deformation are fundamental characteristics of yarns [1-10]. However, with the exception of longitudinal tensile properties, these characteristics, including Poisson's ratio, have not been adequately investigated.

Poisson's ratio is the ratio of transverse to longitudinal strain in tension within the elastic limit for a continuous body. When a tensile force acts longitudinally on a bar having a circular cross-section, the length of the bar extends from $l_{0}$ to $l$ and the diameter shrinks from $W_{0}$ to $W$, as shown in Figure 1.

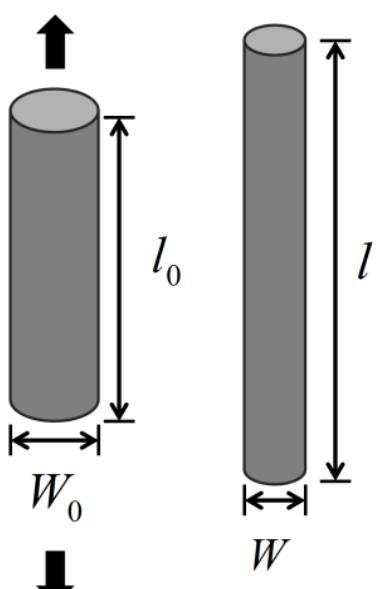

Figure 1 Changes in elongation and diameter in the longitudinal direction

Here, the vertical strain in the longitudinal direction, $\varepsilon$, is expressed by

$$
\varepsilon=\frac{l-l_{o}}{l_{o}} .
$$

The horizontal strain perpendicular to the longitudinal strain, $\varepsilon^{\prime}$, is expressed by

$$
\varepsilon^{\prime}=\frac{W-W_{o}}{W_{o}} .
$$

The ratio of transverse to longitudinal strain, or Poisson's ratio, $v$, is thus 


$$
v=-\frac{\varepsilon^{\prime}}{\varepsilon}
$$

Poisson's ratio for continuous materials is below 0.5. Because textile yarns are neither continuous nor perfectly elastic, in this study, we apply the above definition to the yarns and called it as apparent Poisson's ratio.

The relationships between physical properties and both the tensile property and geometry of the cross-section of a yarn have been widely investigated [11-18, 27]. Barella [19] measured the yarn diameter under different tensile loads using a projection microscope. Carvalho et al. [20] measured the yarn diameter employing coherent optical signal processing. Onions et al. [21] measured yarn thickness using an optical device. Hearle and Merchant [28] measured yarn diameter of nylon spun yarns by a simple microscopic measurement and described effect of tension on the diameter. They also pointed to the difficulty of measuring yarn diameters due to the determining yarn boundary and presence of yarn kinks. However, none of the studies obtained the relation between tensile strain and yarn diameter.

Until now, some researchers have obtained the Poisson's ratio of yarns using diameters measured by a micro-gauge or an image processing of yarn photographs. Sakakibara and Yokoyama [22] measured Poisson's ratio of spun yarn using a tensile tester and a micro-gauge. They considered that Poisson's ratio has different values in two stages of yarn elongation and simulated fabric deformation using these different ratios. Yazaki et al. [23] measured the yarn diameter using a tensile tester and a digital camera for taking photographs. Poisson's ratio of the spun yarn of a carbon nanotube has been investigated [24, 25]. Menghe et al. [26] calculated Poisson's ratio of a carbon-nanotube spun yarn by measuring the diameter against longitudinal strain, employing scanning electron microscopy.

The above methods used a micro-gauge or an image of yarn projected in one direction. However, the cross section of a yarn is not circular and a diameter measurement in one direction could thus result in measurement error. Moreover, tensile load or weight were applied manually in those tests. It thus remains difficult to measure Poisson's ratio for various yarns quickly and automatically. Moreover, a determination of yarn boundary relies on an observer.

In this study, we developed a new tensile tester that measures the omni-directional diameter of a yarn continuously while the yarn is elongated. Using the tester, we measured the longitudinal and transverse strains of yarn samples continuously and quickly, and calculated apparent Poisson's ratio. To obtain yarn diameter, we introduced a statistical method which does not rely on the observer. In addition, we discuss the approximation of the relationship between apparent Poisson's ratio and strain as a power function.

\section{Experimental}

\section{Measurement of Poisson's ratio for yarn}

A new tensile tester equipped with a digital micrometer that omni-directionally measures the diameter of the center part of a yarn in tension was developed as shown in Figure 2. It has upper and lower clamps that move simultaneously to provide elongation. A digital micrometer (Keyence Corporation, LS7000, measurement accuracy $\pm 0.5 \mu \mathrm{m}$ ), which rotates $180^{\circ}$ around the yarn, was used to measure the omni-directional diameters of a yarn during a tensile test. The pulling is stopped at uniform intervals and the diameters are measured to obtain the transverse strain. Load, elongation and diameters of yarn in multiple directions are recorded.

In this experiments, the initial length of a sample yarn was set as $200 \mathrm{~mm}$. We measured the diameter at angles ranging from $0^{\circ}$ to $180^{\circ}$ in intervals of $1^{\circ}$ to account for the nonuniformity of the cross-section of a spun yarn and the average diameter was used for transverse strain at a specified longitudinal strain. The interval of pulling stop was set as $10 \mathrm{~mm}$. The measurements were repeated until just before the yarn broke. The diameter under an initial load of $0.1 \mathrm{~N}$ was used for the initial diameter.

Apparent Poisson's ratio was calculated using longitudinal strains and diameters for each longitudinal strain. The experimental environment had a temperature of $20 \pm 1{ }^{\circ} \mathrm{C}$ and relative humidity of $65 \% \pm 5 \%$.

We tested eight types of yarns, namely five spun yarns, two filament yarns and one nylon monofilament yarn. Table 1 presents details and pictures of the yarn samples. For spun yarns, forty samples were tested to reduce the measurement variation and the average diameter was used as a result. Two filament yarns, twenty samples of P- $\beta$ and P- $\gamma$, were tested since their diameters hardly varied. For the same reason, seven samples of nylon yarn samples were measured.

\section{Rejection of outliers of measured yarn diameters}

Table 1 shows pictures of the hairiness of the spun yarn samples. This hairiness could introduce error into the diameter measurement. We thus removed the error in the diameter due to hairiness through outlier rejection. Assuming that the yarn diameter without hairiness follows a normal distribution, we rejected outliers of the measured diameter. For each longitudinal strain, the diameter of each yarn sample was measured through 180 angles. By performing this series of measurements 40 times, we obtained 7200 diameters. We then rejected outliers of the diameters by applying a Smirnov-Grubbs test [29] which is widely used to detect significantly higher or lower values. In the test, using the largest absolute deviation from the sample mean in units of the sample standard deviation, the outliers are rejected based on the Grubbs' test statistic. By one test, one outlier is rejected. We applied the test to 180 yarn diameters measurements at each strain for all samples, with a significance level of 5\%. Thus, the test was repeated until that the outliers are not detected. The average diameters obtained after the outlier rejection for spun yarns were used for calculation of Poisson's ratio. 


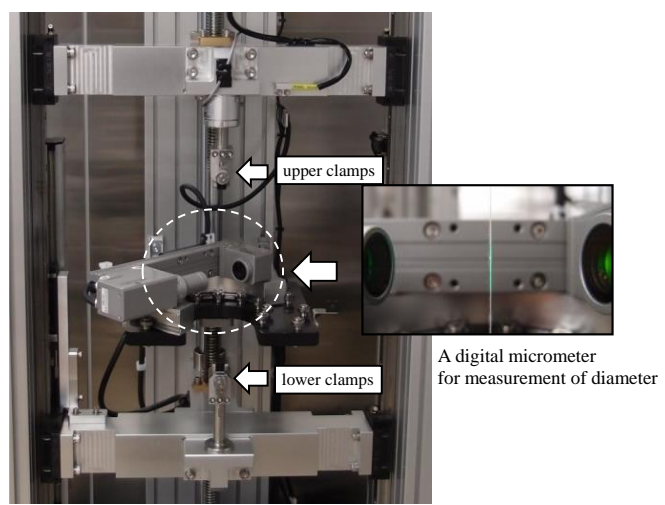

Figure 2 Apparatus for the measurement of the yarn diameter in tension.

Table 1 Specifications of yarn samples

\begin{tabular}{|c|c|c|c|c|}
\hline Sample & $\mathrm{CP}-\alpha$ & $\mathrm{CP}-\beta$ & $\mathrm{CP}-\gamma$ & Ramie \\
\hline Type & Ring spun yarn & Ring spun yarn & Open-end spun yarn & Ring spun yarn \\
\hline Composition & $\begin{array}{c}\text { Cotton } 65 \% \text {, Polyester } \\
35 \%\end{array}$ & $\begin{array}{c}\text { Cotton } 50 \% \text {, Polyester } \\
50 \%\end{array}$ & $\begin{array}{c}\text { Cotton } 50 \% \text {, Polyester } \\
50 \%\end{array}$ & Ramie $100 \%$ \\
\hline Yarn count [tex] & 14.5 & 14.5 & 29.5 & 14.5 \\
\hline Twist $[\mathrm{T} / \mathrm{m}]$ & Z 819 & Z860 & Z 689 & Z 653 \\
\hline Picture & $\overline{100 \mathrm{um}}$ & $100 \mathrm{~mm}$ & & $\frac{200}{100}$ \\
\hline Sample & $\mathrm{P}-\alpha$ & $P-\beta$ & P- $\gamma$ & Nylon \\
\hline Type & Two-ply Ring spun yarn & Two-ply f & ment Yarn & Monofilament \\
\hline Composition & Polyester100\% & Polyester100\% & Polyester100\% & Nylon $100 \%$ \\
\hline Yarn count [tex] & 19.7 & 7.4 & 11.8 & 130.0 \\
\hline Twist $[\mathrm{T} / \mathrm{m}]$ & S 372 & Z 190 & Z358 & - \\
\hline Picture & & & & \\
\hline
\end{tabular}

\section{Results and Discussion}

\section{Relationship between diameter and longitudinal strain}

With developed a new tensile tester equipped with a digital micrometer, we measured the diameter in accordance with the strain of each sample. Figure 3 shows the relationships between the diameter and longitudinal strain for filament yarns and Figures 4-8 the relationships for spun yarns. Table 2 gives the coefficient of variation for the measured diameter.

The diameters of the yarns decreased as the longitudinal strain increased. The diameters for longitudinal strain ranging from $0 \%$ to $2 \%$ were relatively large. This is explained by a reduction in gaps among fibers. The diameters of the spun yarns had a larger coefficient of variation than the filament yarns. Ramie had the largest coefficient of variation among the samples, as shown in Table 2 , owing to the hairiness of the Ramie samples. Figure 9 shows the measured cross sections of P- $\gamma$ and Ramie for the initial load and just before breaking. It is seen that the diameter is less just before breaking than under the initial load. The cross section of P- $\gamma$, which has no hairiness, is an oval shape, whereas the cross section of Ramie, which has hairiness, changed irregularly in the circumferential direction.

To reduce large variations in measurements of diameters, we rejected outlier measurements for spun yarn samples. Figure 10 shows an example of outlier rejection result for Ramie at initial load. As shown in Figure 10, significant picks caused by hairiness were removed. Figures 4-8 show the diameter change of each sample before and after outlier processing. The diameter decreased as the longitudinal strain increased both before and after outlier rejection. After outlier rejection, the coefficient of variation became small as shown in Table 2. In particular, the standard deviation for Ramie, which was the largest among the sample types, became much smaller after outlier rejection processing as shown in Figure 8. 


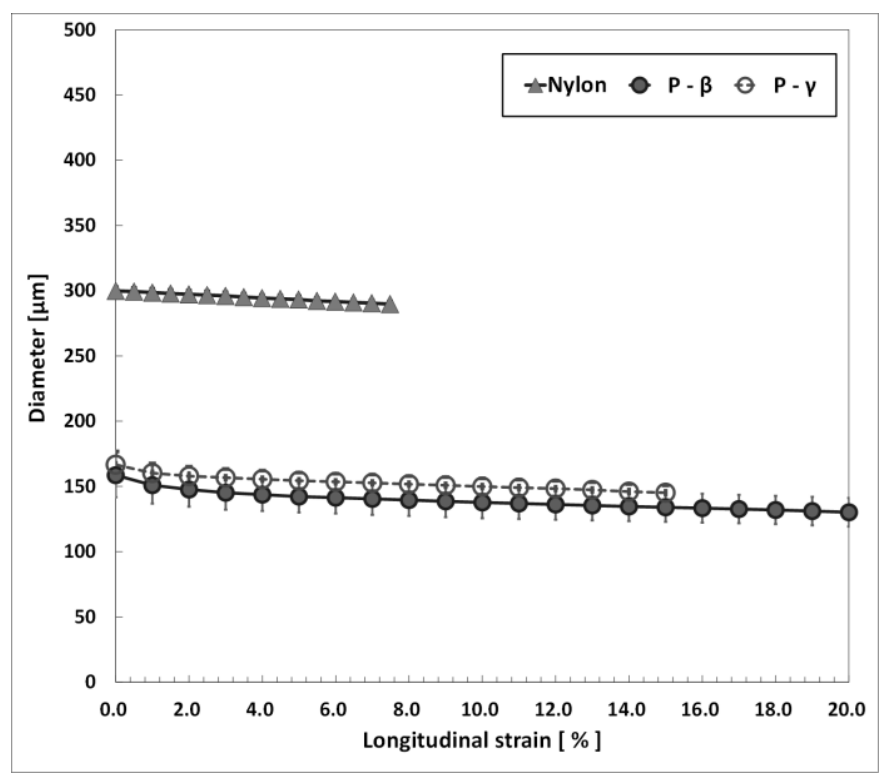

Figure 3 Relationships between diameter and longitudinal strain for P- $\beta, \mathrm{P}-\gamma$ and Nylon samples

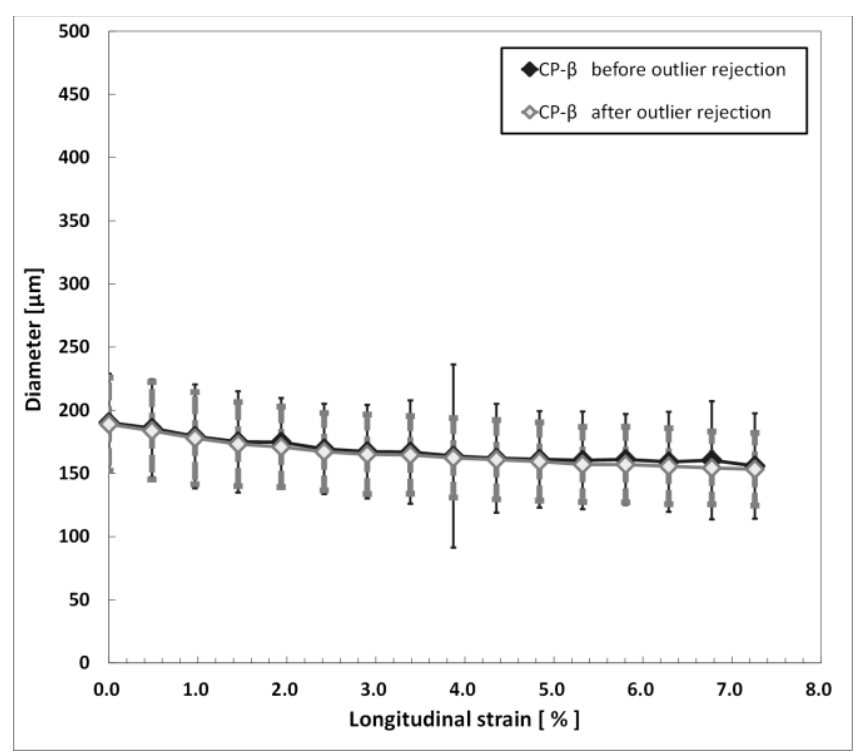

Figure 5 Relationships between diameter and longitudinal strain of CP- $\beta$ before and after outlier rejection

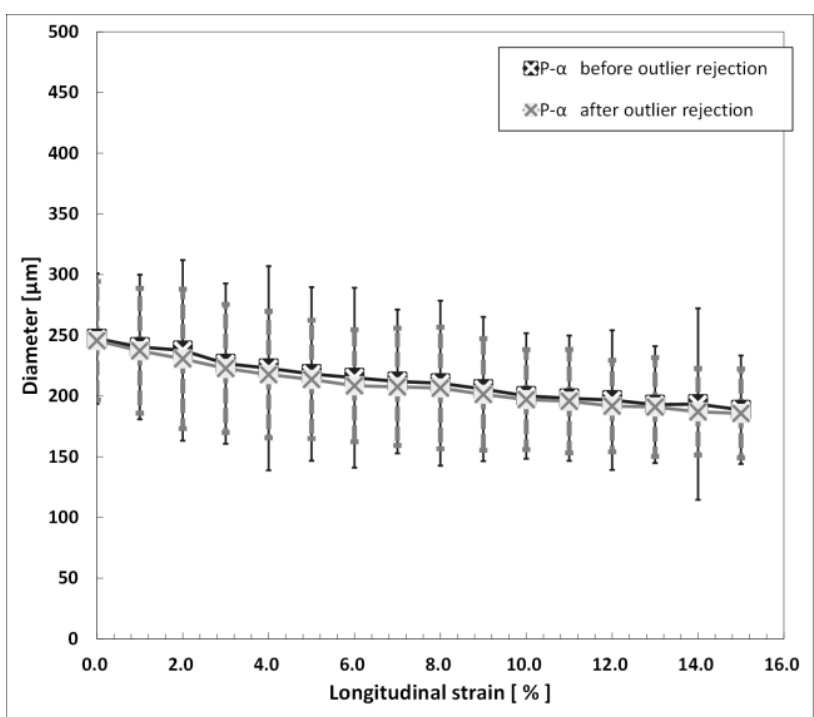

Figure 7 Relationships between diameter and longitudinal strain of $\mathrm{P}-\alpha$ before and after outlier rejection

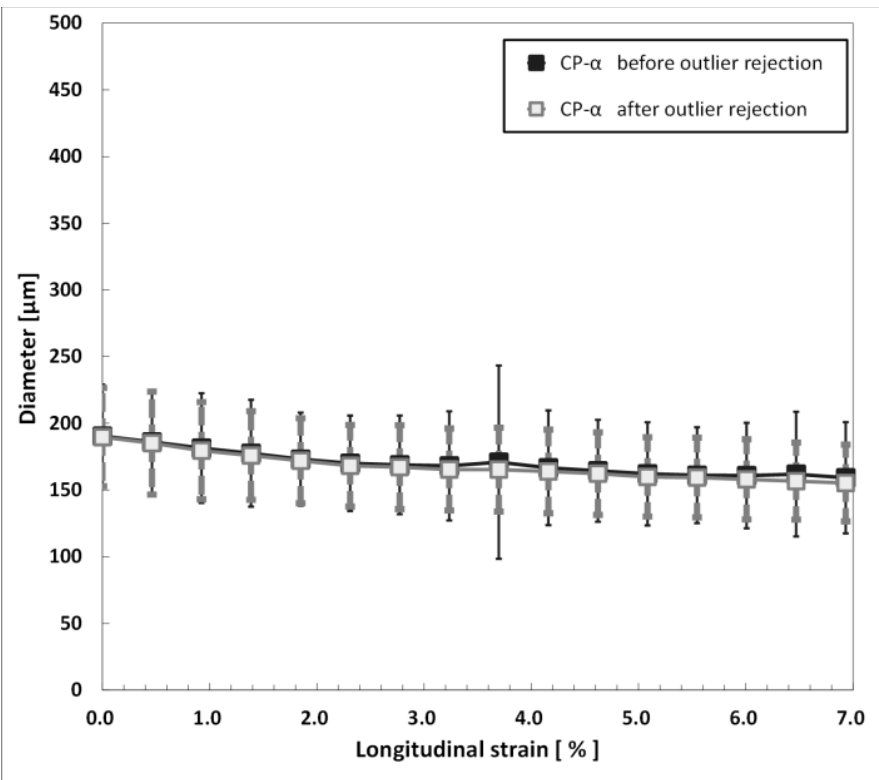

Figure 4 Relationships between diameter and longitudinal strain of CP- $\alpha$ before and after outlier rejection

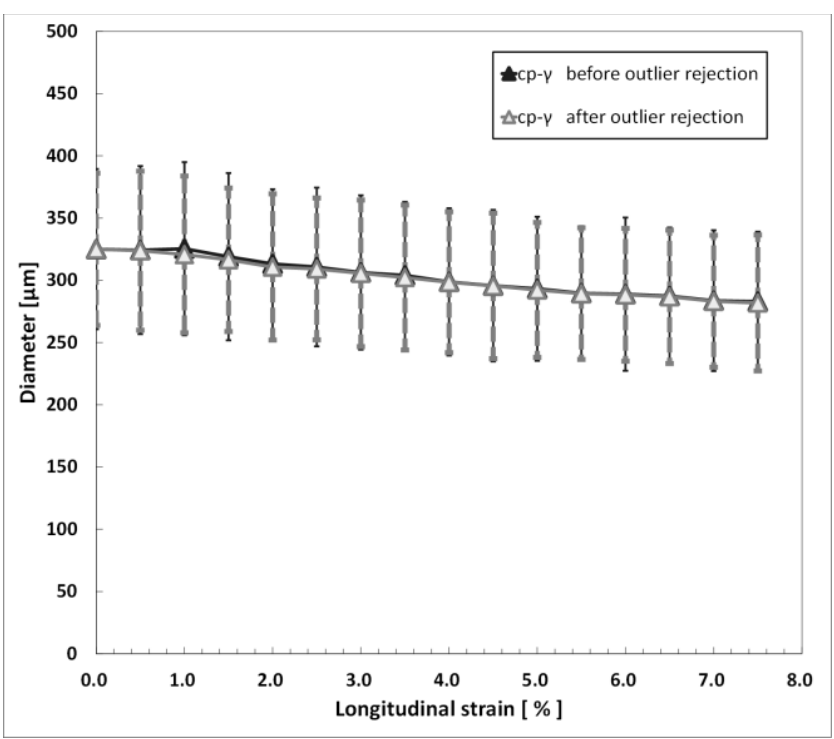

Figure 6 Relationships between diameter and longitudinal strain of $\mathrm{CP}-\gamma$ before and after outlier rejection

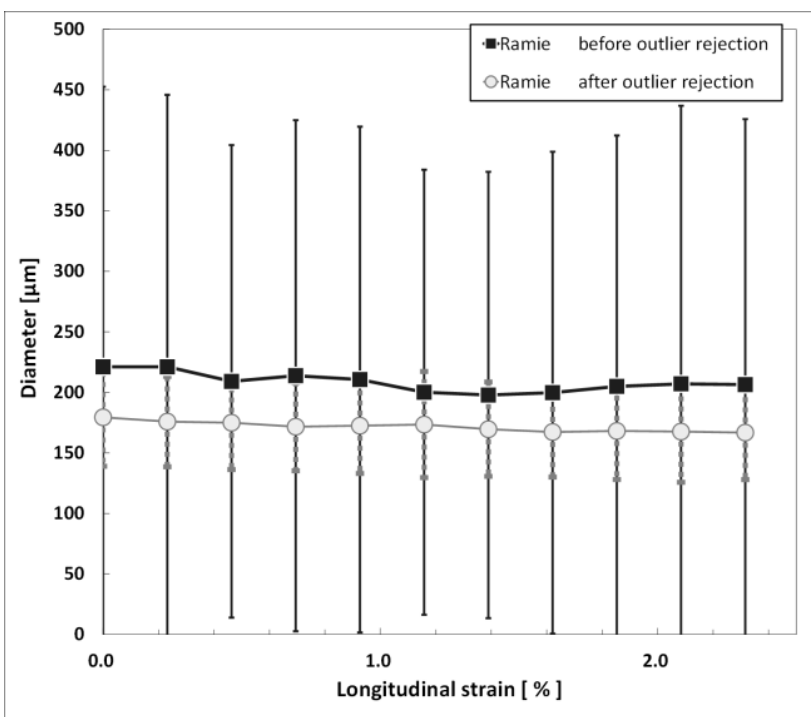

Figure 8 Relationships between diameter and longitudinal strain of Ramie before and after outlier rejection 
Table 2 Coefficient of variation of diameter

\begin{tabular}{|c|c|c|c|c|c|c|c|c|}
\hline \multirow[t]{2}{*}{ Sample } & \multicolumn{2}{|c|}{ CP- $\alpha$} & \multicolumn{2}{|c|}{ CP- $\beta$} & \multicolumn{2}{|c|}{$\mathrm{CP}-\gamma$} & \multicolumn{2}{|c|}{ Ramie } \\
\hline & $\begin{array}{c}\text { Before } \\
\text { outlier } \\
\text { rejection }\end{array}$ & $\begin{array}{c}\text { After } \\
\text { outlier } \\
\text { rejection }\end{array}$ & $\begin{array}{c}\text { Before } \\
\text { outlier } \\
\text { rejection }\end{array}$ & $\begin{array}{c}\text { After } \\
\text { outlier } \\
\text { rejection }\end{array}$ & $\begin{array}{c}\text { Before } \\
\text { outlier } \\
\text { rejection }\end{array}$ & $\begin{array}{c}\text { After } \\
\text { outlier } \\
\text { rejection }\end{array}$ & $\begin{array}{c}\text { Before } \\
\text { outlier } \\
\text { rejection }\end{array}$ & $\begin{array}{c}\text { After } \\
\text { outlier } \\
\text { rejection }\end{array}$ \\
\hline $\operatorname{Max}(\%)$ & 42.4 & 20.8 & 57.2 & 17.7 & 21.4 & 19.7 & 111.0 & 25.3 \\
\hline $\operatorname{Min}(\%)$ & 20.2 & 18.2 & 18.8 & 15.0 & 18.6 & 18.2 & 91.9 & 21.2 \\
\hline Mean $(\%)$ & 24.4 & 19.0 & 25.9 & 16.7 & 20.1 & 18.9 & 100.1 & 23.0 \\
\hline \multirow[t]{2}{*}{ Sample } & \multicolumn{2}{|c|}{$\mathrm{P}-\alpha$} & \multirow{2}{*}{\multicolumn{2}{|c|}{$P-\beta$}} & \multirow{2}{*}{\multicolumn{2}{|c|}{$\mathrm{P}-\gamma$}} & \multirow{2}{*}{\multicolumn{2}{|c|}{ Nylon }} \\
\hline & $\begin{array}{c}\text { Before } \\
\text { outlier } \\
\text { rejection }\end{array}$ & $\begin{array}{c}\text { After } \\
\text { outlier } \\
\text { rejection }\end{array}$ & & & & & & \\
\hline $\operatorname{Max}(\%)$ & 40.8 & 24.9 & \multicolumn{2}{|c|}{6.1} & \multicolumn{2}{|c|}{10.7} & \multicolumn{2}{|c|}{1.2} \\
\hline $\operatorname{Min}(\%)$ & 21.7 & 19.1 & \multicolumn{2}{|c|}{3.9} & \multicolumn{2}{|c|}{8.2} & \multicolumn{2}{|c|}{0.9} \\
\hline Mean $(\%)$ & 29.5 & 22.0 & \multicolumn{2}{|c|}{4.3} & \multicolumn{2}{|c|}{8.7} & \multicolumn{2}{|c|}{1.0} \\
\hline
\end{tabular}

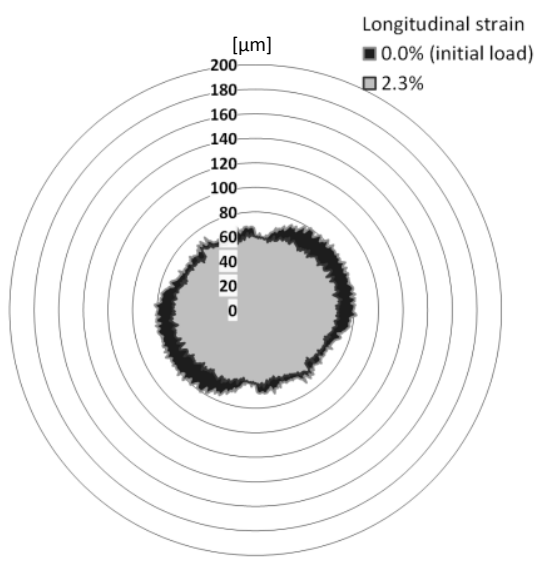

(a) $\mathrm{P}-\gamma$

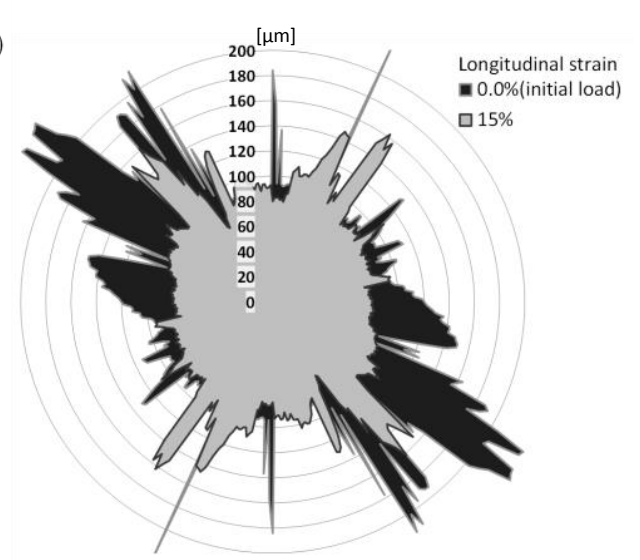

(b) Ramie

Figure 9 Diameter changes of (a) P- $\gamma$ and (b) Ramie

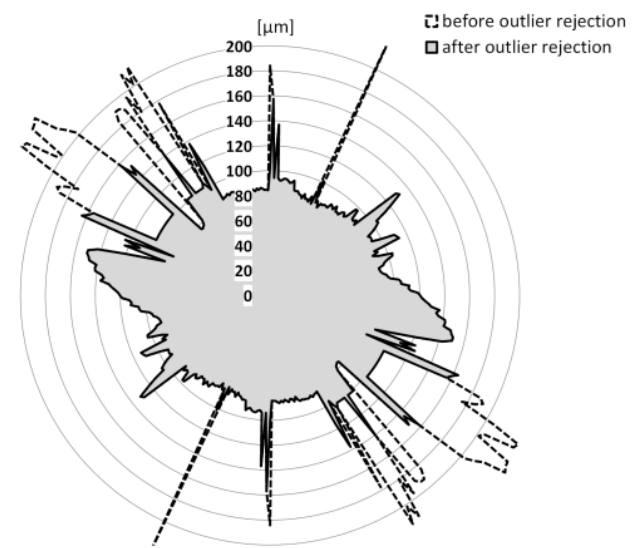

Figure 10 Example of outlier rejection result for Ramie at initial load

\section{Relationship between apparent Poisson's ratio and longitudinal strain}

Apparent Poisson's ratio was calculated from the longitudinal strain and transverse strain obtained from the measured diameter. We used the average diameters after outlier rejection for spun yarn samples to calculate apparent Poisson's ratio. For P- $\beta$, P- $\gamma$ and Nylon samples, the average of the measured diameters was used because it had a small coefficient of variation.

Figure 10 shows the relationship between apparent Poisson's ratio and the longitudinal strain of filament yarns P- $\beta$, P- $\gamma$ and Nylon. Poisson's ratio of P- $\beta$ and P- $\gamma$ were extremely high at low longitudinal strain. Apparent Poisson's ratio then decreased with increasing longitudinal strain for each sample. Apparent Poisson's ratio of Nylon monofilament yarn was 0.35 at longitudinal strain of $0.5 \%$ and then became a constant value of 0.45 .

Figure 11 shows the relationship between apparent Poisson's ratio and the longitudinal strain of the five spun yarn samples. All spun yarn samples except CP- $\gamma$ had a large Poisson's ratio at the initial longitudinal strain. Decreases in apparent Poisson's ratio for those yarns were appreciable in accordance with the increases in the longitudinal strain. However, apparent Poisson's ratio of CP- $\gamma$ increased in the small longitudinal strain range below 2\%. As shown in Table 1, CP- $\gamma$ was an open-end spun yarn. Packing density of open end sun yarns is different from ring spun yarn and filament yarn [30]. The outer packing density of open end spun yarns is smaller than the ones of another yarns. Thus, under small longitudinal strain, outer fiber layers in the yarn could hardly contract while the inner part of yarn stretches. 


\section{Approximation of the relationship between Poisson's ratio and longitudinal strain}

In general, the Poisson's ratio of a continuous material is assumed a constant value regardless of the strain. Our results show that nylon monofilament yarn had a constant apparent Poisson's ratio. However, apparent Poisson's ratios of the multi-filament yarns and spun yarns depended on the longitudinal strain. In analysis and simulation, it is convenient to use a small number of parameters to represent the relationship between the strain and apparent Poisson's ratio. We therefore examined the approximation of the relationship using the power function

$$
\nu(\varepsilon)=a \varepsilon^{b}
$$

Constants of the approximated functions and coefficient of determination, $R^{2}$, are given in Table 3 , where the stain is expressed as a percentage. The approximated curves of all samples are shown in Figures 11 and 12. Constants $b$ of Nylon and CP- $\gamma$ are positive and those of the other samples are negative. Especially, constant $b$ of CP- $\gamma$ is 0.264 . The Poisson ratio of CP- $\gamma$ increases with the increase of longitudinal strain whereas for all other yarns it decreases. It is due to the structure of open-end spun yarn as described above. For Nylon, the constant $b$ is 0.066 which is close to 0 . Thus, the Poisson ratio of Nylon monofilament does not depend on the longitudinal strain. This is due to the constant diameter change of the filament because it has no twist and space between fibers. The coefficients of determination with respect to $\mathrm{P}-\beta$ and $\mathrm{P}-\gamma$ were greater than 0.99 . The coefficients of determination for CP- $\alpha$, $\mathrm{CP}-\beta, \mathrm{P}-\alpha$, and Ramie exceeded 0.8 . The coefficients of determination of Nylon and CP- $\gamma$ were lower because Poisson's ratio was a constant value for small longitudinal strains. It was thus possible to approximate the relationship between apparent Poisson's ratio and longitudinal strain using a power function for multi-filament yarns and spun yarns.

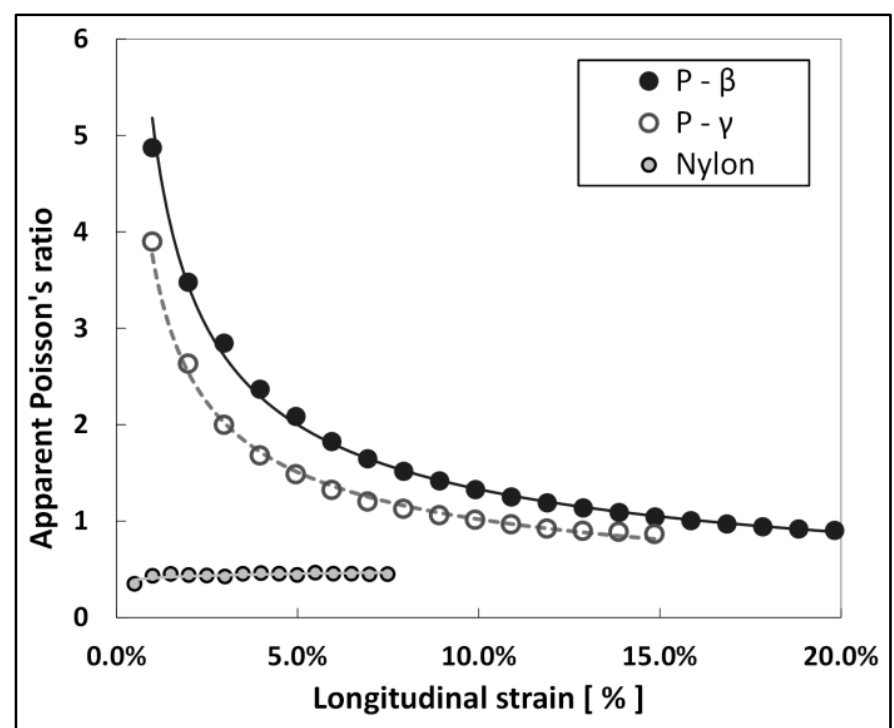

Figure 11 Relationship between apparent Poisson's ratio and the longitudinal strain of filament yarn samples; P- $\beta, \mathrm{P}-\gamma$ and Nylon

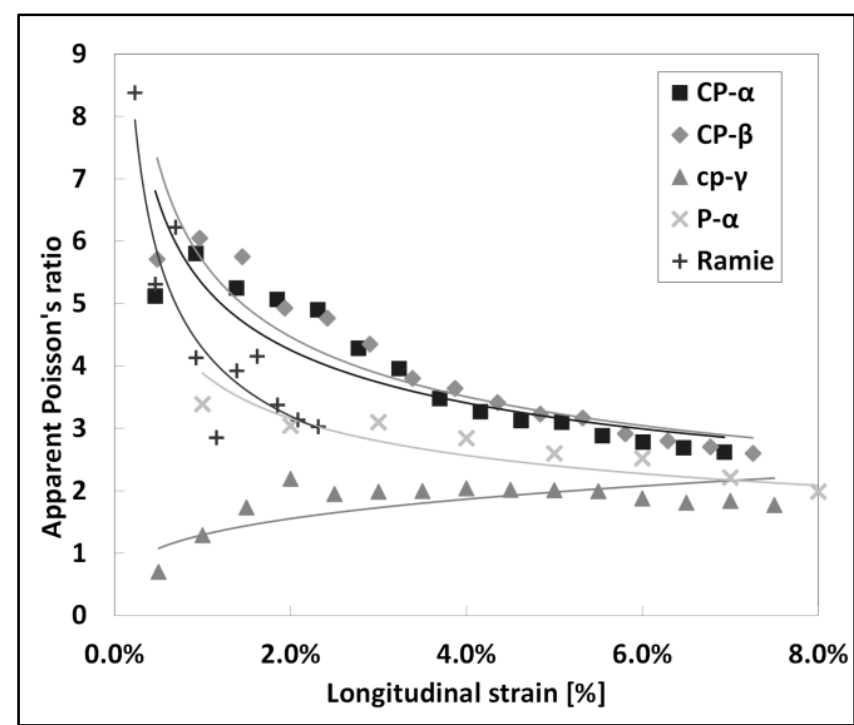

Figure 12 Relationship between apparent Poisson's ratio and the longitudinal strain of spun yarn samples; $\mathrm{CP}-\alpha, \mathrm{CP}-\beta, \mathrm{CP}-$ $\gamma, \mathrm{P}-\alpha$ and Ramie

Table 3 Constants of the approximate curve $v=a \varepsilon^{b}$ and coefficient of determination $\left(R^{2}\right)$

\begin{tabular}{|c|c|c|c|c|}
\hline Sample & CP- $\alpha$ & CP- $\beta$ & CP- $\gamma$ & Ramie \\
\hline$a$ & 1.215 & 1.139 & 4.365 & 0.613 \\
\hline$b$ & -0.321 & -0.349 & 0.264 & -0.422 \\
\hline$R^{2}$ & 0.82 & 0.88 & 0.54 & 0.80 \\
\hline Sample & P- $\alpha$ & P- $\beta$ & P- $\gamma$ & Nylon \\
\hline$a$ & 0.980 & 0.344 & 0.278 & 0.554 \\
\hline$b$ & -0.299 & -0.588 & -0.565 & 0.066 \\
\hline$R^{2}$ & 0.92 & 1.00 & 0.99 & 0.57 \\
\hline
\end{tabular}

\section{Conclusions}

We developed a new tensile tester equipped with a digital micrometer that measures the omni-directional yarn diameter at angles from $0^{\circ}$ to $180^{\circ}$ for an interval of tensile strain during a tensile test. We used the tester to measure the change in diameter under the tensile strain of yarns and calculated apparent Poisson's ratio from the measured diameters. The measured diameters of spun yarns had a large coefficient of variation owing to the hairiness of the yarns. To reduce this variation, we applied statistical processing to reject outliers of the measured diameters. After rejection, we calculated Poisson's ratio from the tensile strains and the mean diameters. It was possible to obtain the apparent Poisson's ratio of yarns that vary according to changes in the longitudinal strain. For multi-filament yarn and ring spun yarn, apparent Poisson's ratio was very high at small longitudinal strain and decreased as the longitudinal strain increased. Apparent Poisson ratio-longitudinal strain curves of multi-filament yarns and ring spun yarns could be approximated using a power function, which can be used in the simulation and mechanical analysis of fabrics. 


\section{References}

1. Tabiei A and Ivanov I. Computational micro-mechanical model of flexible woven fabric for finite element impact simulation. Int J Numer Meth Eng 2002; 53(6): 1259-1276.

2. Eischen JW, Deng S and Clapp TG. Finite-element modeling and control of flexible fabric parts. IEEE Comput Graph 1996; 16(5): 71-80.

3. Magnenat-Thalmann N, Volino P, Bonanni U, Summers IR, Bergamasco M, Salsedo F and Wolter F-E. From physics-based simulation to the touching of textiles: The HAPTEX project. IJVR 2007; 6(3): 35-44.

4. Hearle JWS. The mechanics of twisted yarns: The influence of transverse forces on tensile behaviour. $J$ Text I 1958; 49(8): T389-T408.

5. Loix F, Badel P, Orgéas L, Geindreaua C and Boisse P. Woven fabric permeability: From textile deformation to fluid flow mesoscale simulations. Compos Sci Technol 2008; 68(7-8): 1624-1630.

6. Kang TJ and Yu WR. Drape simulation of woven fabric by using the finite-element method. J Text I 1995; 86(4): 635-648.

7. Volino P and Thalmann NM. Developing simulation techniques for an interactive clothing system. In: International Conference on virtual systems and multimedia, Geneva, 10-12 September 1997, pp.109-118. IEEE.

8. Chen B and Govindaraj M. A parametric study of fabric drape. Text Res J 1996; 66(1): 17-24.

9. Kilby WF. The mechanical properties of twisted continuous-filament yarns. J Text I 1964; 55(12): 539-632.

10. Chen B and Govindaraj M. A physically based model of fabric drape using flexible shell theory. Text Res J 1995; 65(6): 324330.

11. Trelor LRG and Riding G. A theory of the stress-strain properties of continuous-filament yarns. J Text I 1963; 54(4): T156T170.

12. Shinohara A. Mechanical properties of textile assembles. Sen'i Gakkaishi 1989; 45(11): P488-P490.

13. Ozgen B and Gong H. Yarn geometry in woven fabrics. Text Res J 2011; 81(7): 738-745.

14. Placet V, Trivaudey F, Cisse O, Gucheret-Retel V and Lamine Boubakar M. Diameter dependence of the apparent tensile modulus of hemp fibres: A morphological, structural or ultrastructural effect? Composites A 2012; 43: $275-287$.

15. Nitta Y, God K, Noda J and Lee W-I. Cross-sectional area evaluation and tensile properties of alkali-treated kenaf fibres. Composites A 2013; 49: 132-138.

16. Duckett KE, Goswami BC and Ramey HH Jr. Mechanical properties of cotton/polyester yarns: Part I: Contributions of interfiber friction to breaking energy. Text Res J 1979; 49(5), 262-267.

17. Yilmaz D, Göktepe F, Göktepe Ö and Kremenakova D. Packing density of compact yarns. Text Res J $2007 ; 77$ (9): $661-667$.

18. Yang K, Tao X-M, Xu B-G and Lam J. Structure and properties of low twist short-staple singles ring spun yarns. Text Res $J$ 2007; 77(9): 675-685.

19. Barella A. Law of critical yarn diameter and twist influence on yarn characteristics. Text Res J 1950; 20(4): 249-258.

20. Carvalho V. H., Cardoso P. J., Belsley M. S., Vasconcelos R. M. and Soares F. O. Yarn diameter measurements using coherent optical signal processing. IEEE Sens J 2008; 8(11): 1785-1793.

21. Onions WJ, Oxtoby E and Townend PP. 22-Factors affecting the thickness and compressibility of worsted-spun yarns. $J$ Text I 1967; 58(7): 293-315.

22. Sakakibara K and Yokoyama A. Numerical simulation of deformation behavior of fabric structures under bi-axial load. $J$ Text Eng 2007; 53(2): 79-86.

23. Yazaki Y, Takatera M and Shimizu Y. Light transmission properties of plain knitted fabrics in uniaxial and biaxial extension. Sen'i Gakkaishi 2005; 61(7): P183-P190.

24. Miao M. Yarn spun from carbon nanotube forests: Production, structure, properties and applications. Particuology 2013; 11(4): 378-393.

25. Sugano K, Kurata M and Kawada H. Evaluation of mechanical properties of untwisted carbon nanotube yarn for application to composite materials. Carbon 2014; 78: 356-365.

26. Miao M, McDonnell J, Vuckovic L and Hawkins SC. Poisson's ratio and porosity of carbon nanotube dry-spun yarns. Carbon 2010; 48(10): 2802-2811.

27. Hearle, J. W., Grosberg, P., and Backer, S., Structural mechanics of fibers, yarns, and fabrics, 1969, Wiley-Interscience, New York, 61-100

28. Hearle, J. W. S., and V. B. Merchant. "Relations between specific volume, count, and twist of spun nylon yarns." Textile Research Journal 1963; 33(6): 417-424.

29. Grubbs, F. E., Sample criteria for testing outlying observations. The Annals of Mathematical Statistics, 1950, $27-58$.

30. Lawrence, C. A. (2003). Fundamentals of spun yarn technology, CRC press LLC, Florida, 353-354 